\title{
The Kieswerk of Pointe Saint-Mathieu and the Atlantic Wall
}

\section{G. Tomezzoli}

European Patent Office, Munich, Germany

Email: gtomezzoli@epo.org

Received 21 August 2015; accepted 11 October 2015; published 14 October 2015

Copyright (C) 2015 by author and Scientific Research Publishing Inc.

This work is licensed under the Creative Commons Attribution International License (CC BY). http://creativecommons.org/licenses/by/4.0/

(c) (i) Open Access

\begin{abstract}
In this article a construction of the Atlantic Wall discovered on 02/01/2006 near the Pointe Saint Mathieu (Finistère, France) is identified and its purpose is clarified. It witnessed the presence, during the World War II, at Pointe Saint-Mathieu, of a Kieswerk or pebble factory in which the pebbles and/or crushed pebbles of the Ero Vili were stored and distributed. The Kieswerk was very likely to have participated in the construction of the Atlantic Wall fortifications of the Pointe Saint-Mathieu.
\end{abstract}

\section{Keywords}

2nd World War, Atlantic Wall, Kieswerk, Fortification, Bunkers, Saint-Mathieu, France, Ero Vili

\section{Introduction}

Looking to the impressive defensive fortifications of the Atlantic Wall (Chazette et al., 1995; Dupont \& Peyle, 1994; Duquesne, 1976), sometime the attention of the people is distracted from the enormous efforts and the logistic structure behind that, which allowed the construction of them. Many of the components of this structure have disappeared, but sometime here and there some of them can still be recognized and identified.

The Kieswerk of Pointe Saint-Mathieu $\left(48^{\circ} 20^{\prime} 10.5^{\prime \prime} \mathrm{N}, 04^{\circ} 46^{\prime} 2.9^{\prime \prime} \mathrm{W}\right)$

On 02/01/2006, during an excursion on Pointe-Saint Mathieu (Finistère, France) (cf. Figure 1), a construction of the Atlantic Wall was discovered. It was provisionally identified as a construction of type and purpose unknown and then forgotten. Now, in the light of a previous publication (Tomezzoli, 2015), the construction (cf. Figure 2) can be easily identified as a silo for storing pebbles and/or crushed pebbles and appears to belong to a small Kieswerk or pebbles factory similar, in some aspects, to that of the Camp Todt at Prat ar Hastel on the Municipality of Tréguennec (Bohn, 2014; Doaré \& Le Berre, 2006; Tomezzoli, 2015).

At the pebble factory of Camp Todt (Tomezzoli, 2015), the Ero Vili pebbles collected on the Tronoën beach were loaded on convoys of wagonettes. Locomotives Decauville brought each convoy on the top of a massive 


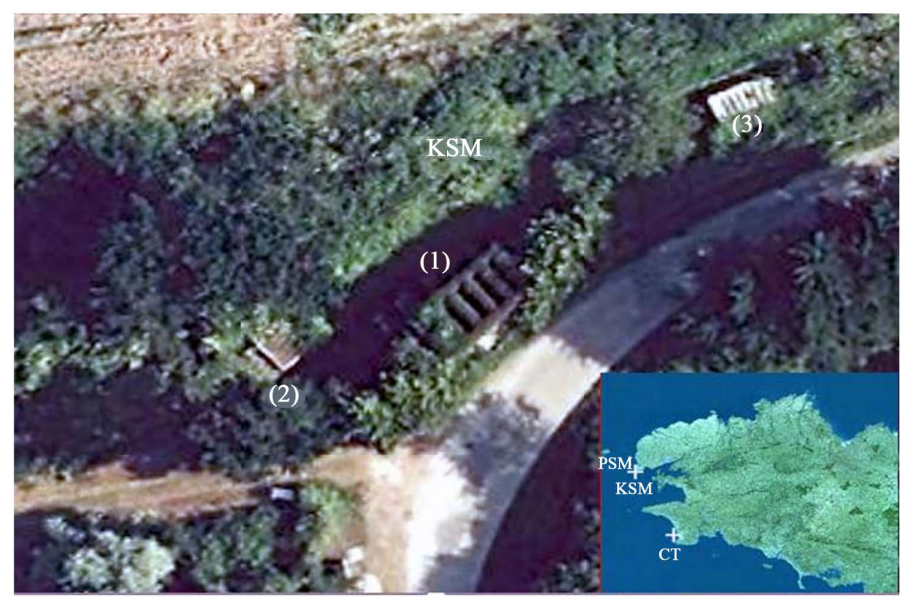

Figure 1. Brittany: CT Camp Todt, KSM Kieswerk, PSM Pointe Saint-Mathieu: (1) first silo forstoring pebbles, (2) concrete barrack and (3) possible second silo or concrete barrack.

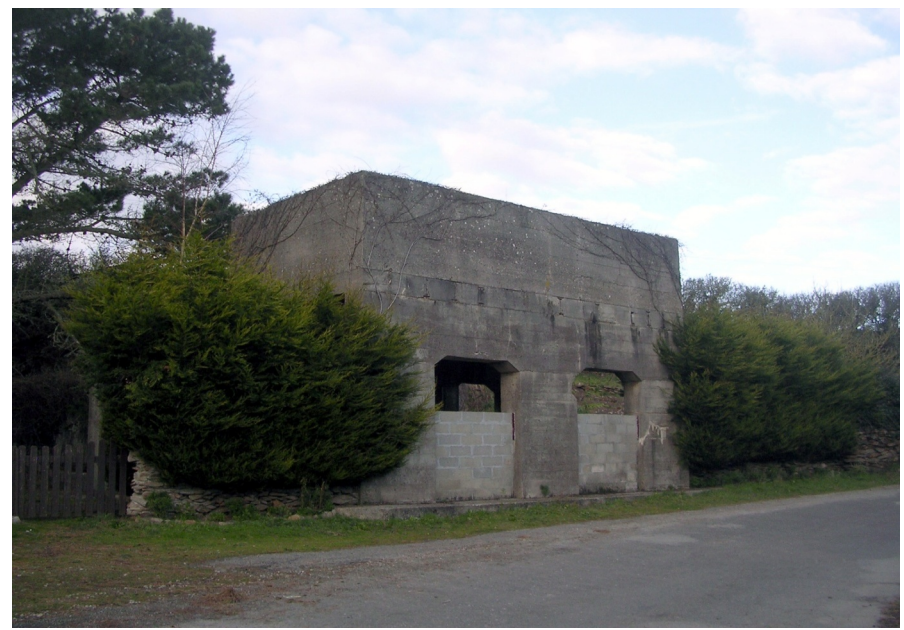

Figure 2. Kieswerk: first silo-overview.

wall about 150 meters long, 2 meters wide and 10 meters high. From that height, workers manually toppled each wagonette so as to drop the pebbles into screening silos. From those silos, the small pebbles directly usable in construction fell into the wagons of a railway convoy parked at the base of the wall. The too large pebbles not usable in the state were collected in other convoys of wagonettes driven by loco-tractors and stored outside a crusher building (about $20 \times 13$ meters). Conveyor belts brought the pebbles towards three horizontal jaw crushers and a vertical cylinder crusher inside the building. The crushed pebbles were stored in a first concrete silo with four compartments inside the building and in a second silo (about $10 \times 5.40$ meters) provided with five hoppers at about $30 \mathrm{~m}$ from the building.

At the pebble factory of Pointe Saint Mathieu no remains witnessed the presence of a crushers building and a massive wall. Identifiable (cf. Figure 1) were a first silo, a barrack and a possible second silo or barrack (cf. Figure 2).

The first silo (1) is about 10 meters long, 5 meters large and 8 meters high. The imprints of the wooden bars of the formwork on the concrete confirm that it is a typical work of the German masonry. The silo is provided with five pebble compartments, each superimposed to one hopper. The hoppers permitted the loading of pebbles on vehicles parked on an underlying loading way. The compartments were filled with pebbles and/or crushed pebbles by a possible conveyor belt mechanism of which concrete supports were still recognizable. From where the pebbles came remains a mystery. The silo is in a good state of preservation and does not present damages due to combats (Figure 3 and Figure 4). 


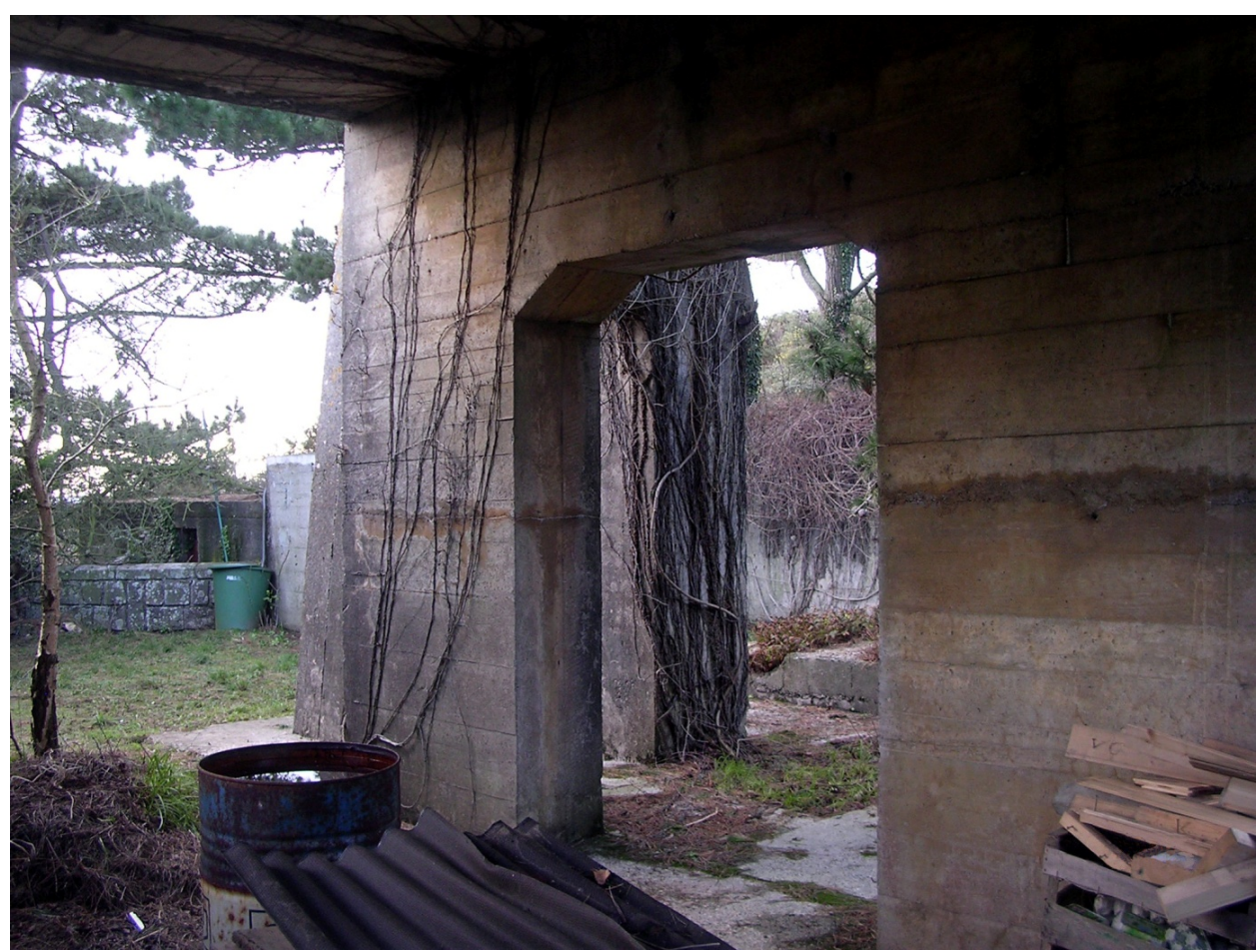

Figure 3. Kieswerk: first silo-loading way.
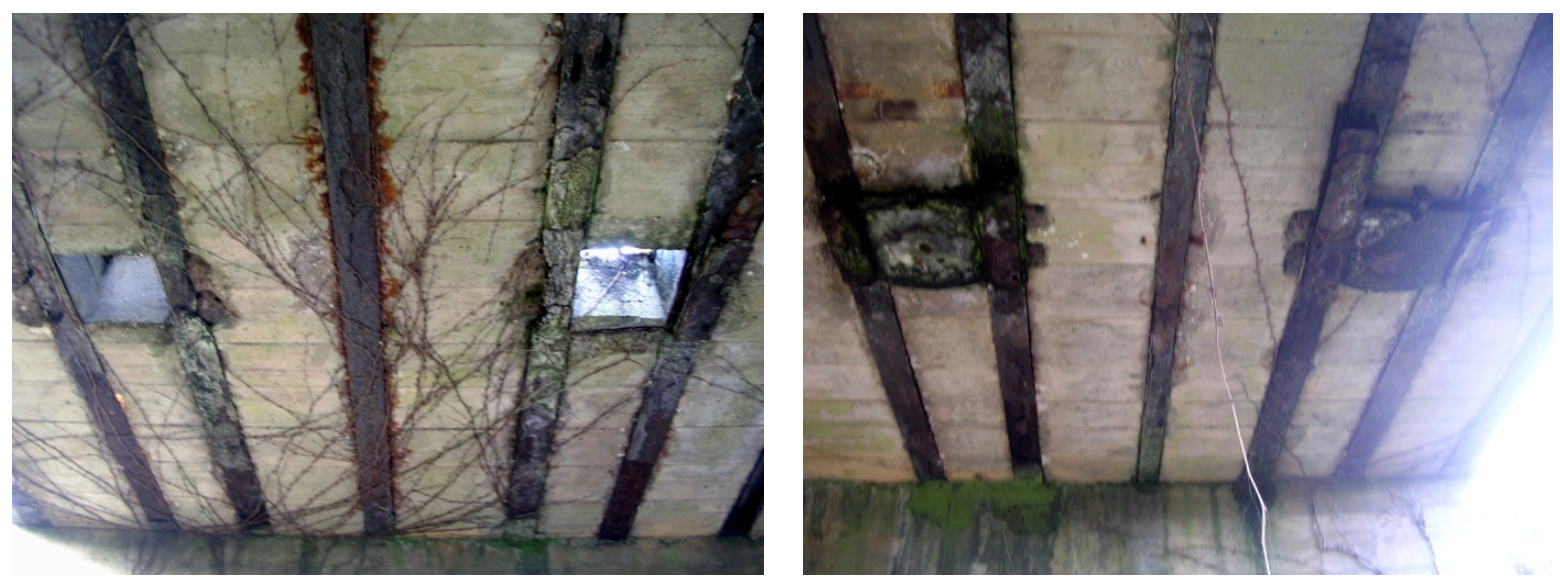

Figure 4. Kieswerk: first silo_-opened and closed hoppers on the loading way.

The absence of traces of railway lines on the loading way and around the silo suggested that the pebbles were loaded on trucks for a transport on short distances. Therefore, the Kieswerk was very likely to have participated in the construction of the Atlantic Wall fortifications of Pointe Saint-Mathieu (Figure 5 and Figure 6), in particular of the nearby MKB (Marine Coastal Battery) Graf-Spee (cf. Figures 7-9) of Keringar and MKB vonHoltzendorff (cf. Figure 10 and Figure 11).

A concrete barrack (2) about $5 \times 3$ meters is located at about 5 meters from the first silo. Its recent aspect and the impossibility to have a close look to its masonry let in doubt about whether it is contemporary to the first silo or built later. A possible second silo or barrack (3) about $5 \times 2.5$ meters on a private field and encircled by the vegetation was not accessible.

\section{Conclusion}

I am happy to have visited the vestiges of the Kieswerks of Camp Todt and of Pointe Saint-Mathieu. These op- 


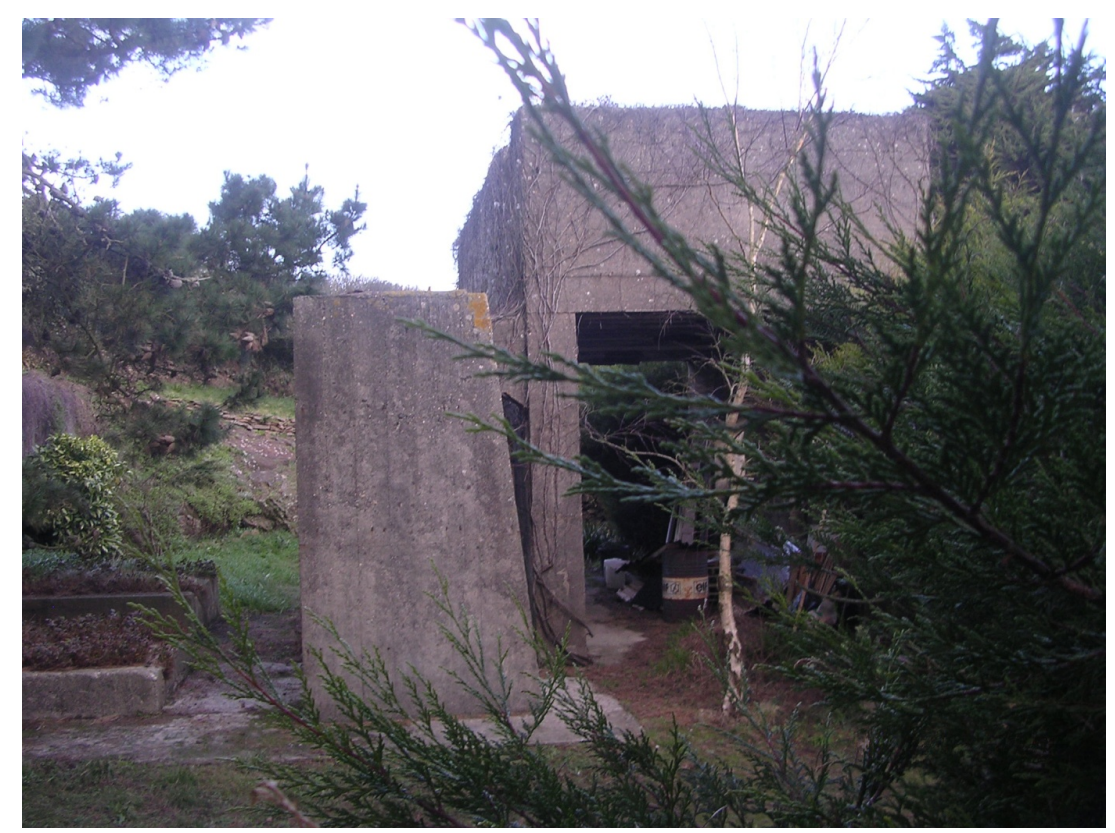

Figure 5. Kieswerk: first silo-concrete support of the loading conveyor belt mechanism.
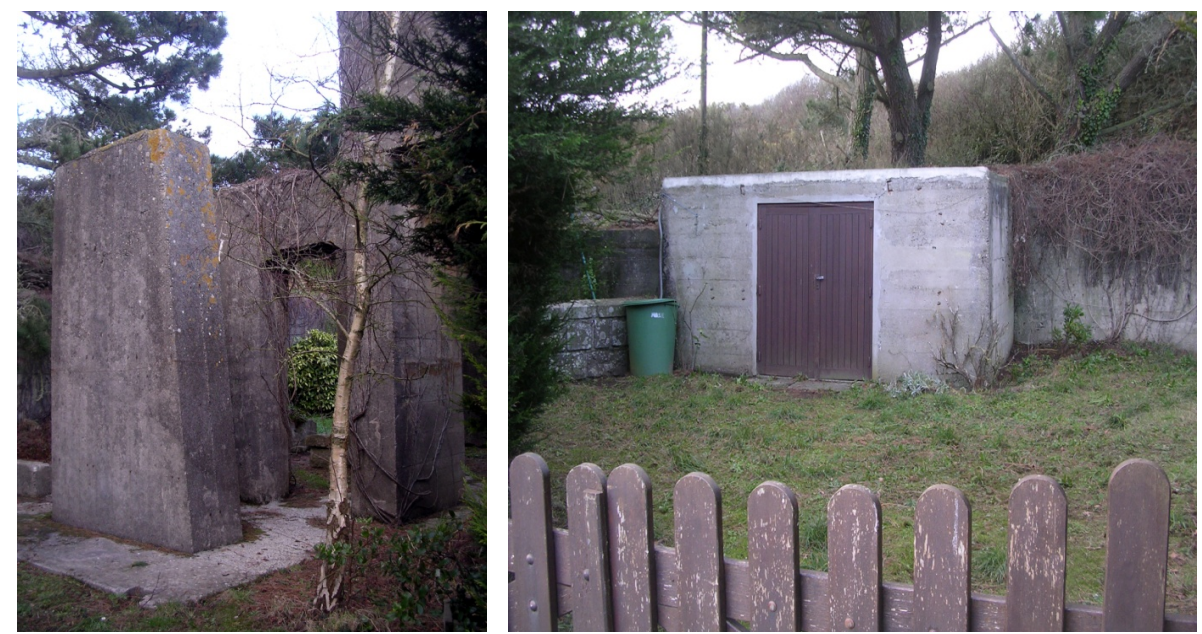

Figure 6. Kieswerk: first silo concrete supports of the loading conveyor belt mechanism and concrete barrack.

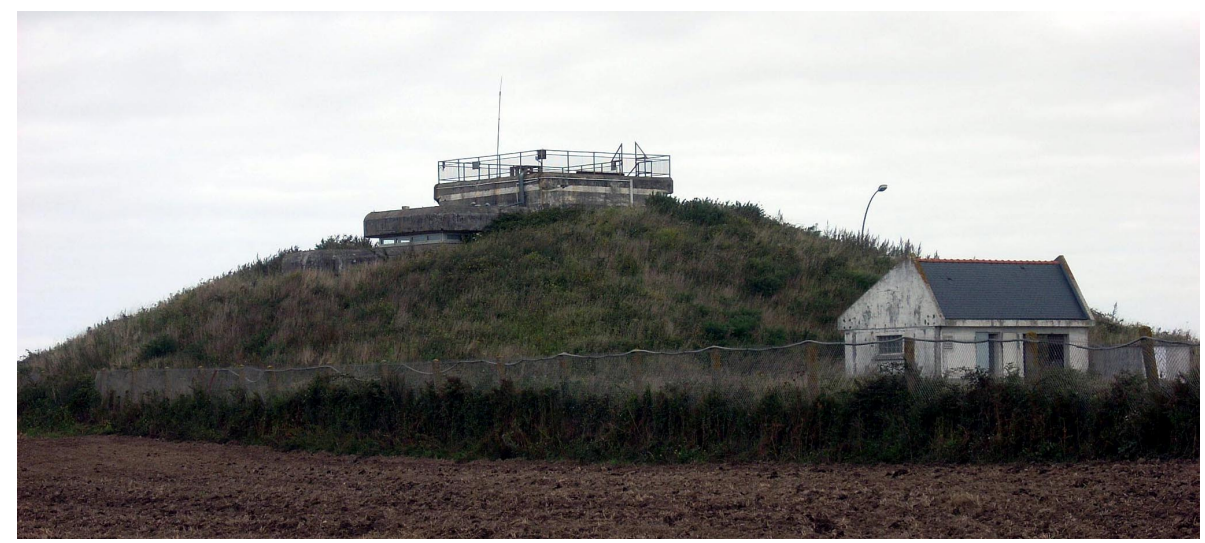

Figure 7. RE 302 MKB Graf Spee-fire control bunker S 414. 


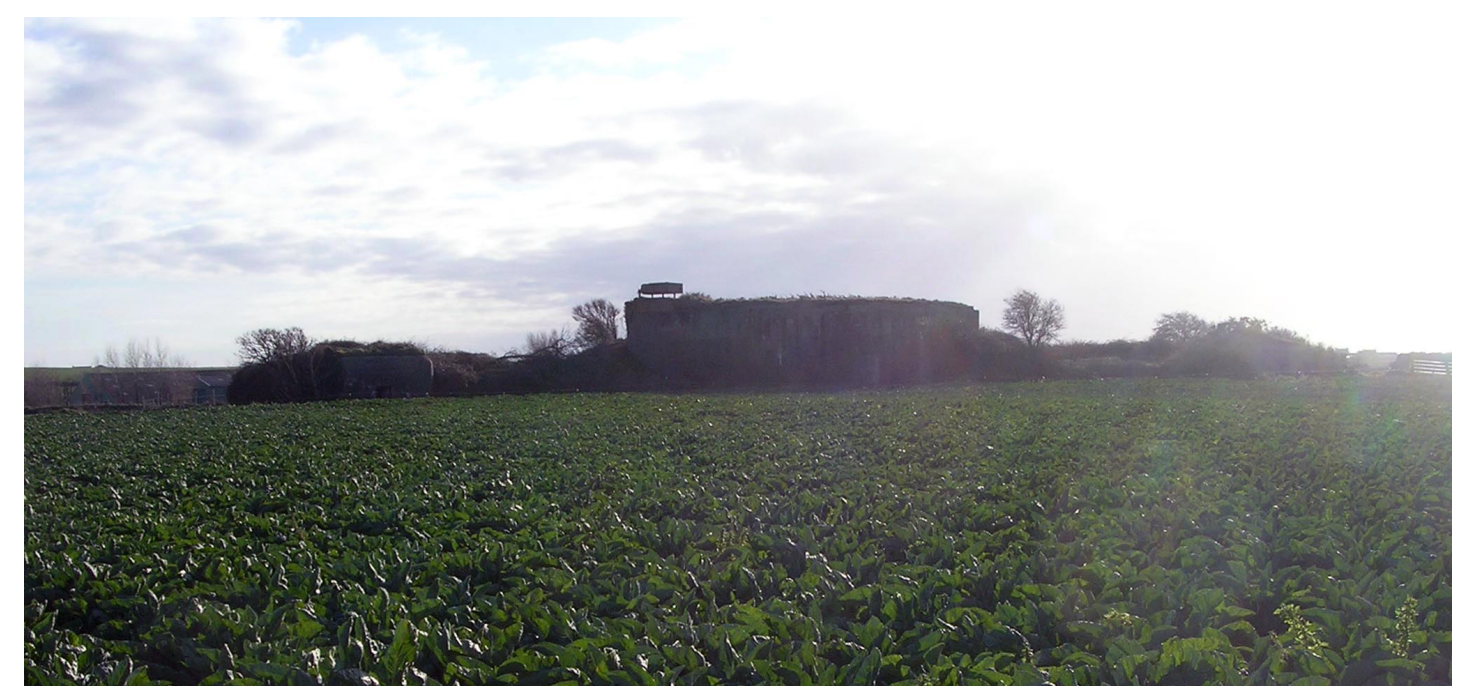

Figure 8. RE 302 MKB Graf Spee-protective bunker for $280 \mathrm{~mm}$ gun.

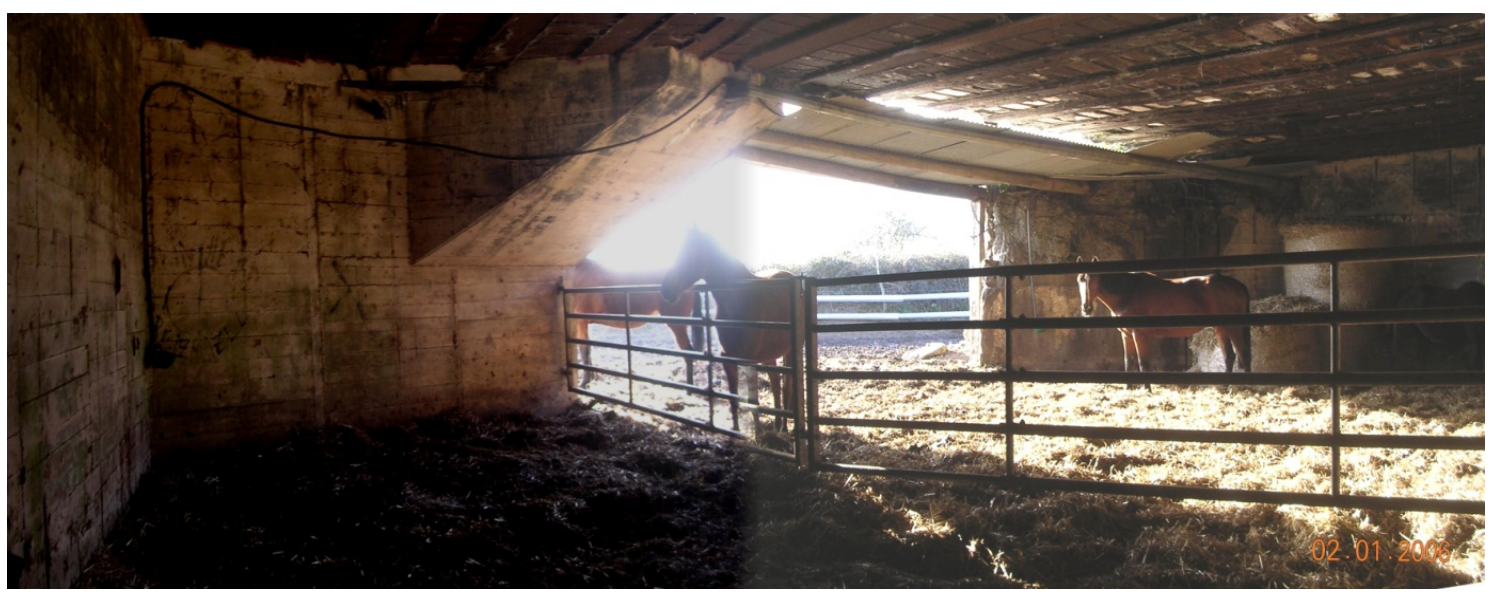

Figure 9. RE $302 \mathrm{MKB}$ Graf Spee-interior of the protective bunker for $280 \mathrm{~mm}$ gun.

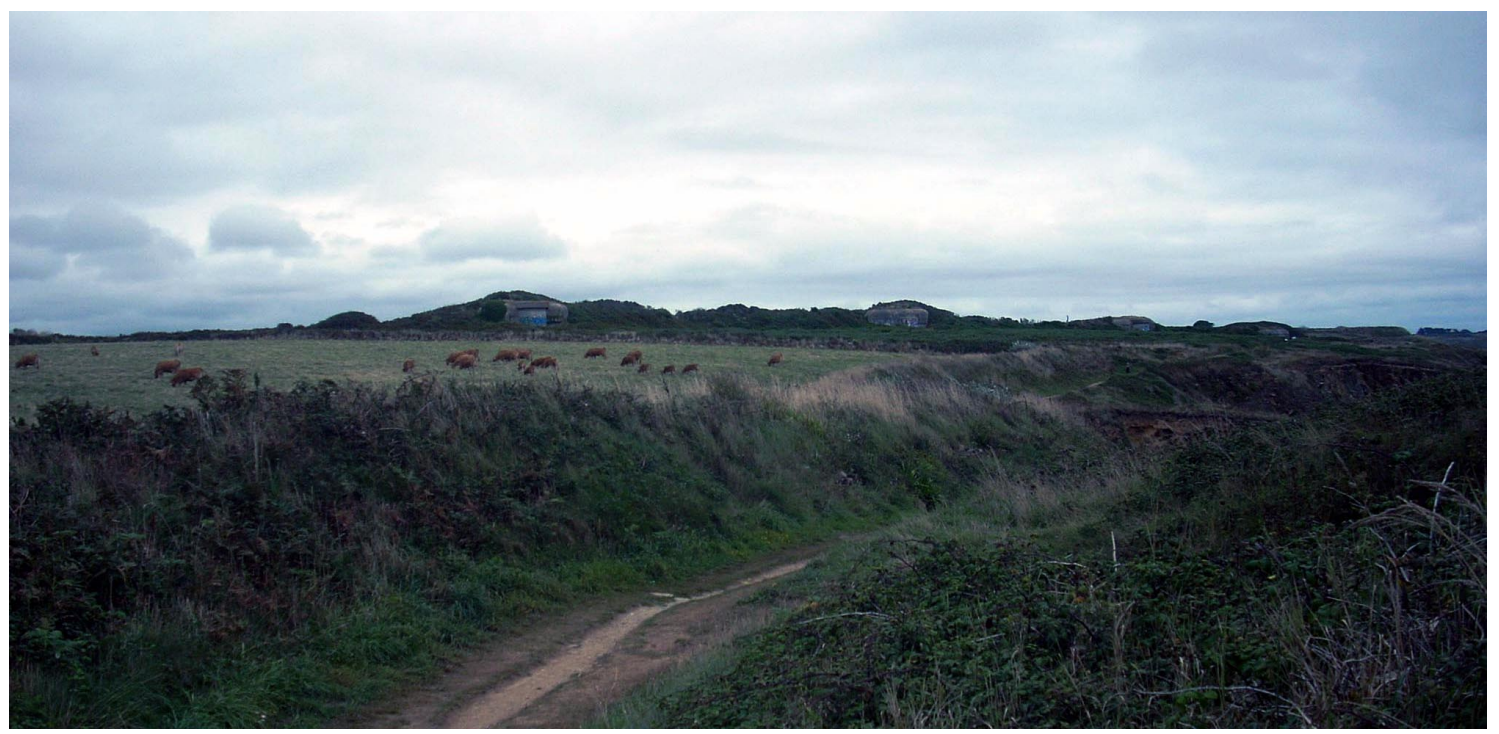

Figure 10. RE 305 MKB von-Holtzendorff-overview. 

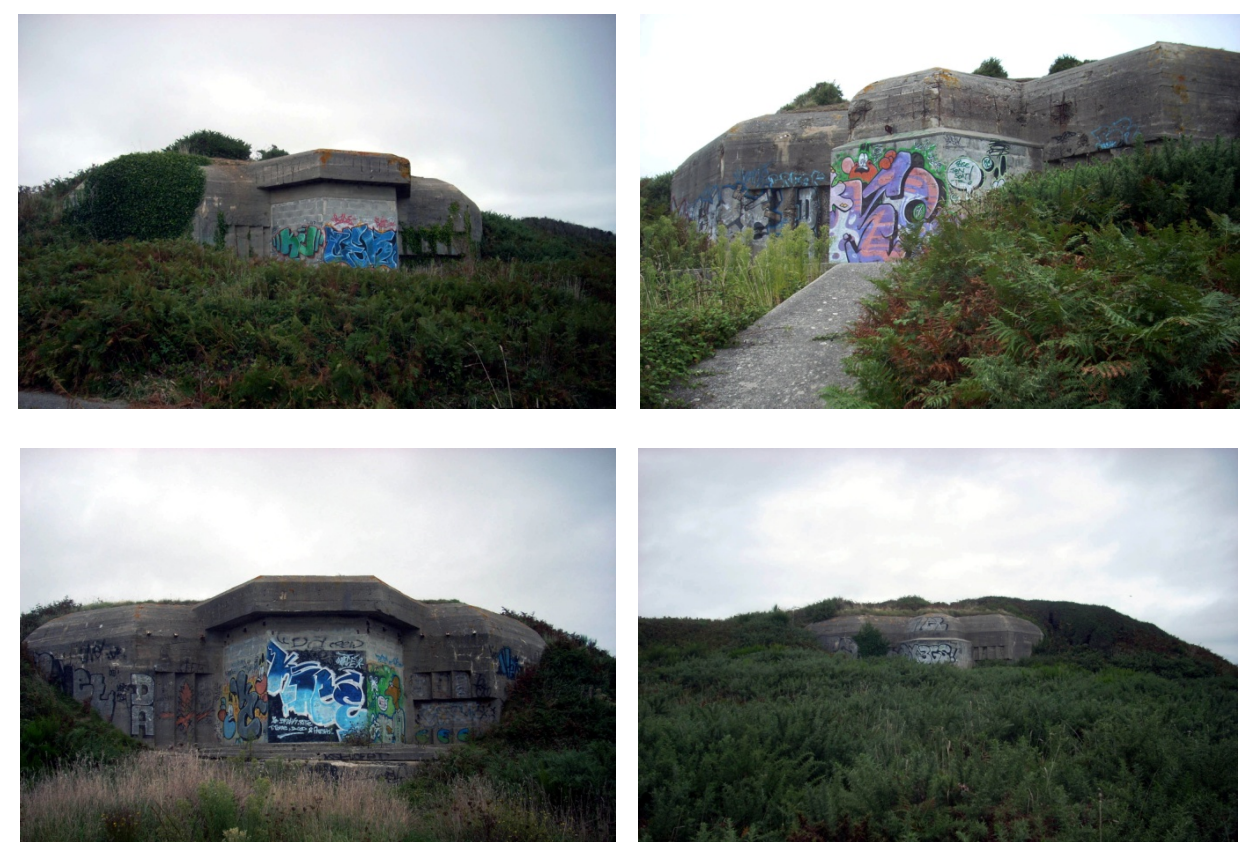

Figure 11. RE $305 \mathrm{MKB}$ von-Holtzendorff-special design bunkers for $150 \mathrm{~mm} \mathrm{SKC/28}$ gun.

portunities have provided me with information about a non-secondary aspect of the construction of the Atlantic Wall and I hope that this article will stimulate other studies on this subject.

\section{References}

Bohn, É. (2014). Tréguennec. L'usine à galets des nazis, le Télégramme, photo d'archives Y. Marzin. http://www.letelegramme.fr/histoire/treguennec-l-usine-a-galets-des-nazis-23-02-2014-10048893.php?annonces=1

Chazette, A., Destouches, A., \& Paich, B. (1995). Album Mémorial Atlantikwall, Le Mur de L'Atlantique en France 19401944, ed. Heimdal, ISBN 2.84048-088-3.

Doaré, J.-J., \& Le Berre, A. (2006). Pointe de Cornouaille 1940-1944. AS3P, ISBN 2-9524073-0-4.

Dupont, A., \& Peyle, E. (1994). Le Mur de l'Atlantique sur la Côte d'Emeraude, ed. Danclau, ISBN 2-907019-20-1.

Duquesne, R. (1976). Normandie 44 Le Mur de L'Atlantique, Batteries d'Artillerie Côtière, ed. Heimdal, Bayeux.

Tomezzoli, G. (2015). The Ero Vili and the Atlantic Wall. Advances in Anthropology, 5. 